\title{
Development of a Novel Experimental In Vitro Model of Isothiocyanate-induced Apoptosis in Human Malignant Melanoma Cells
}

\author{
THEODORA MANTSO ${ }^{1 *}$, ARISTEIDIS P. SFAKIANOS ${ }^{1 *}$, AITHNE ATKINSON ${ }^{1}$, IOANNIS ANESTOPOULOS $^{2}$, \\ MELINA MITSIOGIANNI ${ }^{3}$, SOTIRIOS BOTAITIS ${ }^{4}$, SEBACHEDIN PERENTE ${ }^{4}$, CONSTANTINOS SIMOPOULOS $^{4}$, \\ STAVROS VASILEIADIS ${ }^{2}$, RODRIGO FRANCO ${ }^{5,6}$, AGLAIA PAPPA $^{2}$ and MIHALIS I. PANAYIOTIDIS ${ }^{1,3}$ \\ ${ }^{1}$ School of Life Sciences, Heriot Watt University, Edinburgh, Scotland, U.K.; \\ ${ }^{2}$ Department of Molecular \& Cell Biology, Democritus University of Thrace, Alexandroupolis, Greece; \\ ${ }^{3}$ Department of Applied Sciences, Northumbria University, Newcastle Upon Tyne, U.K.; \\ ${ }^{4}$ Second Department of Surgery, Democritus University of Thrace, Alexandroupolis, Greece; \\ ${ }^{5}$ Redox Biology Centre, University of Nebraska, Lincoln, NE, U.S.A.; \\ ${ }^{6}$ School of Veterinary Medicine \& Biomedical Sciences, University of Nebraska, Lincoln, NE, U.S.A.
}

\begin{abstract}
Background: Isothiocyanates are constituents of cruciferous vegetables which have been associated with reduced cancer risk partially through their ability to induce apoptosis in malignant cells including melanoma. Materials and Methods: We have utilized human malignant melanoma (A375), epidermoid carcinoma (A431) and immortalized keratinocyte ( $\mathrm{HaCaT}$ ) cells exposed to various isothiocyanates, under different experimental conditions. Results: An experimental in vitro model utilizing low isothiocyanate concentrations (0.1-5 $\mu M$ for $48 \mathrm{~h}$ with all treatments being refreshed after 24h) was shown to be (i) most efficient in exerting an anti-cancer effect when compared to higher concentrations (5-100 $\mu \mathrm{M}$ for 24 or $48 \mathrm{~h}$ added as a single bolus) and (ii) specific to A375 cells while A431 and HaCaT cells remained unaffected. Such effect involved the activation of several caspases including (iii) initiator caspases 8, 9, 4 (indicating the involvement of intrinsic, extrinsic and endoplasmic reticulum-based pathways) and (iv) effector caspases 3, 7 and 6. Conclusion: Utilization of low isothiocyanate concentrations (under the conditions described
\end{abstract}

This article is freely accessible online.

*These Authors contributed equally to this study.

Correspondence to: Professor Mihalis I. Panayiotidis, Department of Applied Sciences, Northumbria University, Ellison Building A516, Newcastle Upon Tyne, NE1 8ST, U.K. Tel: +44 01912274305,e-mail: m.panagiotidis@ northumbria.ac.uk

Key Words: Isothiocyanates, sulforaphane, phenethyl isothiocyanate, benzyl isothiocyanate, malignant melanoma, apoptosis. herein) exerts an anti-cancer effect specific to human malignant melanoma cells thus providing a therapeutic basis for their utilization in management of the disease.

Malignant melanoma is the fifth most common cancer in UK with its incidence rates being continuously rising faster than any other malignancy (1). Epidemiological studies suggest that an increased dietary consumption of cruciferous vegetables can reduce cancer incidence. These effects can be attributed to the high levels of glucosinolates (GSLs) present which are sulphur-containing glycosides and precursors for a group of compounds called isothiocyanates (ITCs) (2). Briefly, upon mechanical disruption of the plant cell wall (e.g. by chewing), the enzyme myrosinase is released which then catalyses the hydrolysis of GSLs to ITCs, with subsequent release of $\mathrm{HSO}_{4}{ }^{-}$and D-glucose (3). Different GSLs can form different ITCs, since glucoraphanin acts as the precursor for sulforaphane (SFN), gluconasturtin for phenethyl isothiocyanate (PEITC) and glucotropaeolin for benzyl isothiocyanate (BITC) (4). There is much speculation as to how ITCs may exhibit their chemotherapeutic effects, but the likelihood is that multiple molecular events are responsible. Potential biochemical mechanisms include (i) inhibition of carcinogen activity via suppression of phase I enzymes in xenobiotic metabolism, (ii) stimulation of phase II enzymes and (iii) induction of apoptosis $(5,6)$. Despite many reports demonstrating ITCs' effectiveness against different cancers there have been a limited number of studies investigating their ability to induce apoptosis in human malignant melanoma cells (7) which their results are dependent on the utilization of high concentrations of ITCs. 
In this study, we aimed to develop a novel experimental in vitro model based on the utilization of low ITC concentrations capable of inducing apoptosis in human malignant melanoma (A375) cells. For this reason, our objectives were to (i) establish an experimental model of exposure to various ITCs and, furthermore, to (ii) characterize ITCs' anti-cancer activities by determining the induction of a number of caspases descriptive of various apoptotic pathways including those of intrinsic, extrinsic and ER-dependent origin.

\section{Materials and Methods}

Chemicals. SFN was obtained from Abcam (Cambridge, UK) whereas PEITC and BITC from Sigma-Aldrich (St. Louis, MO, USA). All compounds were dissolved in DMSO (Sigma-Aldrich) and stored at $-20^{\circ} \mathrm{C}$. DMEM medium, trypsin, PBS, FBS, LGlutamine and Penicillin/Streptomycin were obtained from Labtech International Ltd (East Sussex, UK). Resazurin sodium salt was supplied by Sigma-Aldrich. All chemicals were of analytical grade and purchased from Sigma-Aldrich, Applichem (Darmstadt, Germany) and Invitrogen (Carlsbad, CA, USA). BSA was obtained from Biosera (Boussens, France). Protease inhibitor cocktail was obtained from Roche (Basel, Switzerland). PVDF membranes (0.45 and $0.2 \mu \mathrm{m}$ ) were purchased from Millipore (Bedford, MA, USA). The pre-stained pink protein ladder was from Nippon Genetics Europe (Dueren, Germany). Primary (anti-PARP, anti-procaspase 3, anti-procaspase 6, anti-procaspase 7 and anti-lamin $\mathrm{A} / \mathrm{C}$ ) and horseradish peroxidase-conjugated secondary antibodies were purchased from Cell Signalling Technology (Danvers, MA, USA) whereas anti- $\beta$-actin from Sigma-Aldrich and enhanced chemiluminescence western blotting substrate kit from Pierce Thermo Scientific (Waltham, MA, USA).

Cell culture and treatment protocols. A375 and A431 cells were purchased from Sigma-Aldrich (St. Louis, MO, USA). HaCaT cells were a kind gift from Dr Sharon Broby (Dermal Toxicology and Effects Group; Centre for Radiation, Chemical and Environmental Hazards; Public Health England, UK). All cell lines were cultured in DMEM medium (10\% FBS, 2 mM L-Glutamine and $1 \%$ penicillin/streptomycin) and maintained in a humidified atmosphere at $37^{\circ} \mathrm{C}$ and $5 \% \mathrm{CO}_{2}$. SFN, PEITC, BITC or vehicle were added either as (i) a single bolus concentration ranging between 5-100 $\mu \mathrm{M}$ for 24 to $48 \mathrm{~h}$ or (ii) at $0.1-5 \mu \mathrm{M}$ for $48 \mathrm{~h}$ with all treatments being refreshed after $24 \mathrm{~h}$.

Cell viability assay. Cells $\left(5 \times 10^{3}\right)$ were seeded in $100 \mu \mathrm{l}$ of complete medium into 96-well plates and kept overnight in the incubator before they were treated with either one of the treatment protocols. Cell viability was assessed by using the Alamar blue assay where in brief, resazurin sodium salt was dissolved in PBS $(1 \mathrm{mg} / \mathrm{ml}$ final concentration) and $10 \mu \mathrm{l}$ of reagent were added into each well of the 96-well plates. After $4 \mathrm{~h}$ of incubation, fluorescence intensity was measured at $560_{\mathrm{Exc}} / 590_{\mathrm{Em}} \mathrm{nm}$ by using a Spectramax M5 multi-mode plate reader (Sunnyvale, CA, USA).

Caspase activity assay. The caspase family fluorometric substrate kit II plus from Abcam (Cambridge, UK) was used according to the manufacturer's instructions. Cell lysates were prepared and 150-200 $\mu \mathrm{g}$ of protein extracts were incubated with each respective substrate for $1 \mathrm{~h}$ at $37^{\circ} \mathrm{C}$. Fluorescence intensity was monitored at $400_{\mathrm{Exc}} / 505_{\mathrm{Em}}$ $\mathrm{nm}$ by using a Spectramax M5 multi-mode plate reader.

Preparation of cell lysates and protein determination. Cells $\left(0.8 \times 10^{6}\right)$ were plated in $100-\mathrm{mm}$ dishes and cultured overnight at $37^{\circ} \mathrm{C}$. Next day, cells were treated with $0.1-5 \mu \mathrm{M}$ of each ITC for $48 \mathrm{~h}$ (with all treatments being refreshed after $24 \mathrm{~h}$ ) and then trypsinized, collected in micro-centrifuge tubes and washed twice with PBS. Cell pellets were lysed in lysis buffer (10 mM HEPES at pH 7.9, $10 \mathrm{mM} \mathrm{KCl}, 0.1 \mathrm{mM}$ EDTA, $1.5 \mathrm{mM} \mathrm{MgCl}_{2}, 0.2 \% \mathrm{NP} 40$ ) and supplemented with a protease inhibitors' cocktail $(20 \mathrm{mM} \beta$ glycerophosphate and $0.2 \mathrm{mM} \mathrm{Na}_{3} \mathrm{VO}_{4}$ ). Then, they were left on ice while periodically vortexed over a $30 \mathrm{~min}$ period. Cell lysates were centrifuged at $14,000 \times g$ for $15 \mathrm{~min}$ at $4^{\circ} \mathrm{C}$ and supernatants were transferred in fresh tubes. Protein content was determined by utilizing the BCA protein assay from Thermo Scientific (Waltham, MA, USA) according to manufacturer's instructions. Protein extracts were stored at $-20^{\circ} \mathrm{C}$ until usage

Western immunoblotting. Forty micrograms $(40 \mu \mathrm{g})$ of cellular protein extracts were separated by SDS-polyacrylamide gels and transferred electrophoretically onto PVDF membranes (either 0.45 or $0.2 \mu \mathrm{m}$ ). The blots were blocked in 5\% non-fat milk powder in TBST buffer (50 mM Tris- $\mathrm{HCl}, 150 \mathrm{mM} \mathrm{NaCl}$ at $\mathrm{pH} 7.6$ and $0.1 \%$ Tween-20) for $2 \mathrm{~h}$ at room temperature. The membranes were incubated with the appropriate primary antibody $(1: 1,000$ for anti-PARP, anti-procaspase 3 , anti-procaspase 6, anti-procaspase 7, anti-lamin $\mathrm{A} / \mathrm{C}$ and 1:2,000 for anti- $\beta$-actin) overnight at $4^{\circ} \mathrm{C}$ under agitation. Next day, the membranes were incubated with the appropriate (mouse or rabbit) horseradish peroxidase-conjugated secondary antibody $(1: 2,000)$ for $1 \mathrm{~h}$ at room temperature under agitation, after being washed three times with TBST. Membranes were washed three times with TBST and once with distilled water. Labeled protein bands were detected by utilizing enhanced chemi-luminescence.

Statistical analysis. Measurements for cell viability assays were performed in quintuplicate $(n=5)$ while those for caspase activity assays in triplicates $(\mathrm{n}=3)$ and all values are expressed as mean \pm standard error. Statistical analysis was performed by means of a Student $t$-test. A value of $p<0.05$ was considered statistically significant.

\section{Results}

The effect of three different ITCs (SFN, PEITC and BITC) was evaluated at a range of single bolus concentrations (5$100 \mu \mathrm{M}$ ) in both human A375 malignant melanoma (Figure 1A-C) and $\mathrm{HaCaT}$ immortalized keratinocyte cells (Figure 1D-F) after $24 \mathrm{~h}$ and $48 \mathrm{~h}$ of treatment. Addition of a single bolus of each ITC concentration statistically significantly decreased $(p<0.05)$ both $\mathrm{A} 375$ and $\mathrm{HaCaT}$ cell viability levels in a concentration-dependent manner. More specifically, SFN decreased cell viability at $10 \mu \mathrm{M}$ onwards (24-48h) in A375 (Figure 1A) and $\mathrm{HaCaT}$ (Figure 1D) cells. PEITC also decreased cell viability levels but at a concentration of $25 \mu \mathrm{M}$ onwards (24-48h) for A375 (Figure 1B) and $10 \mu \mathrm{M}$ onwards (24-48h) for HaCaT (Figure 1E) cells. BITC exerted the 
A375

(A)

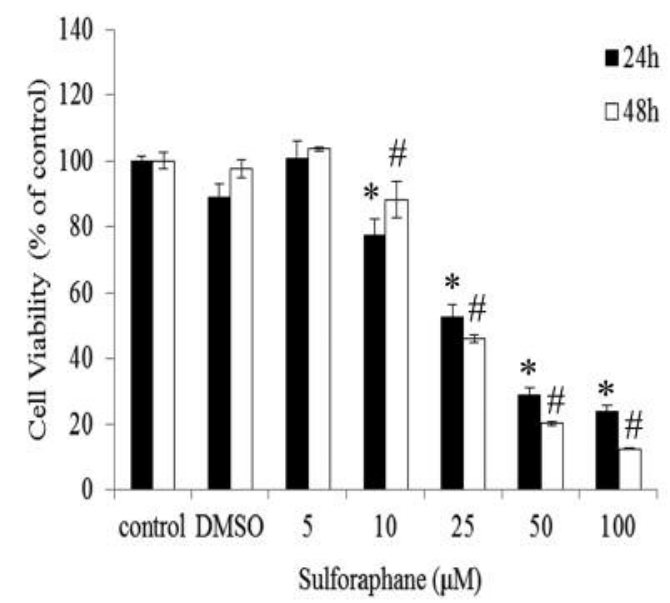

(C)

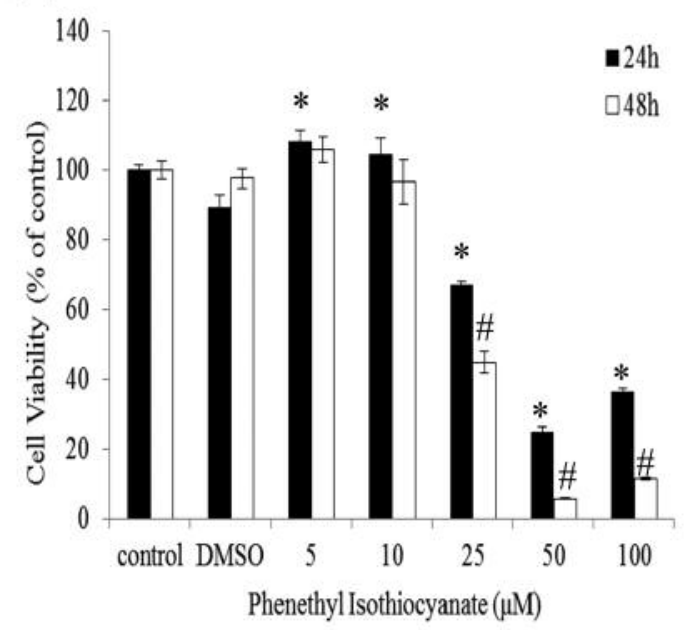

(E)

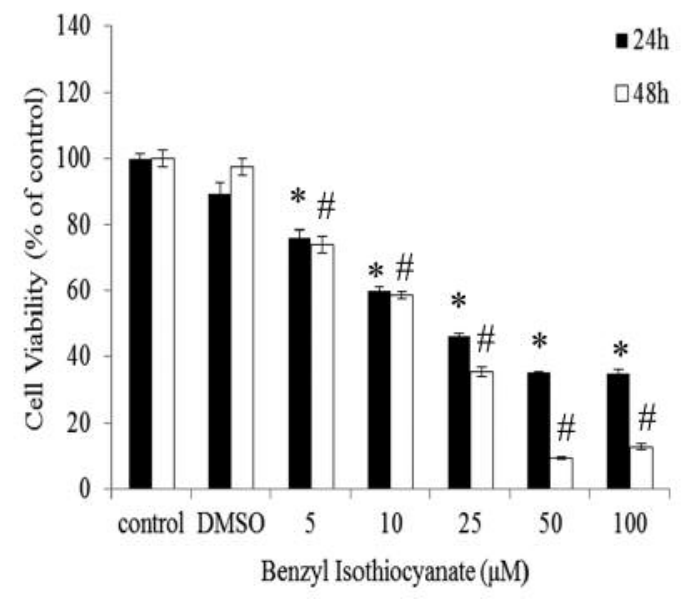

\section{$\mathrm{HaCaT}$}

(B)

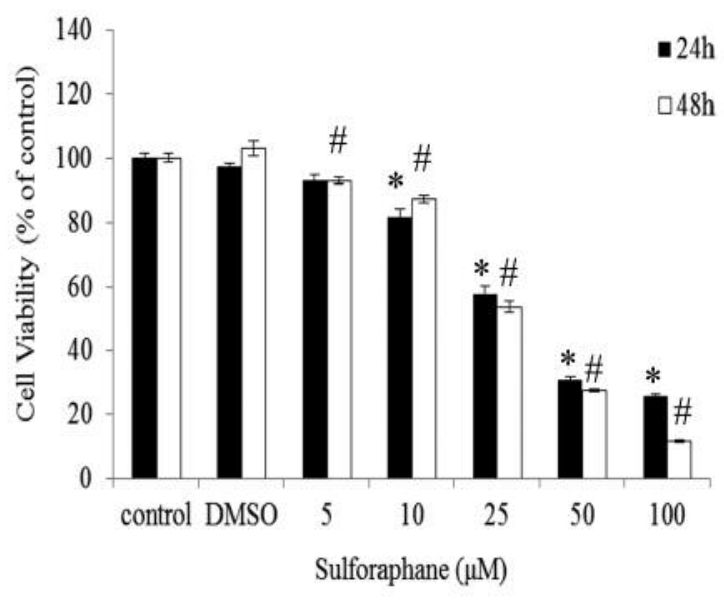

(D)

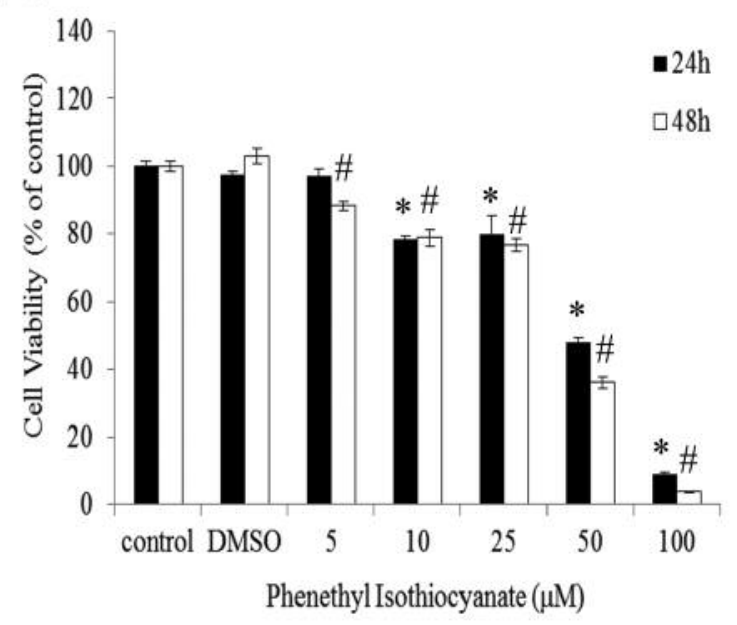

(F)

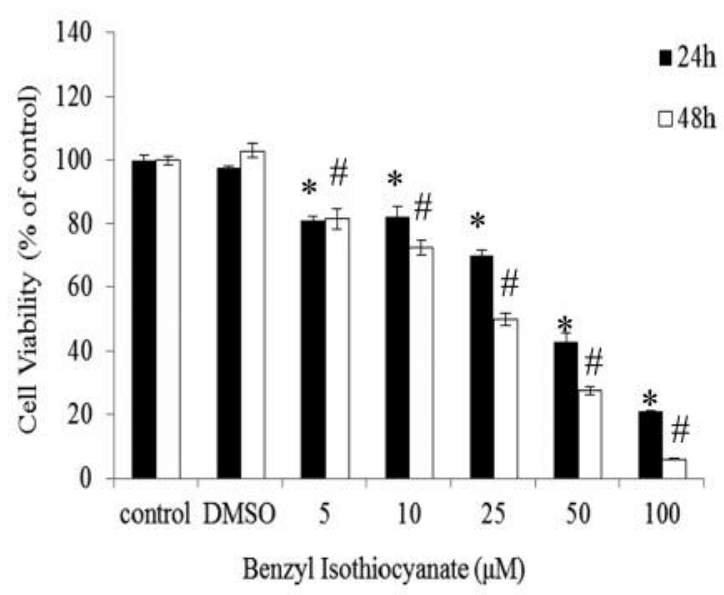

Figure 1. The effect of different concentrations of ITCs in A375 and HaCaT cells after 24 and 48 h of treatment. Cells were subjected at a single bolus concentration ranging between 5-100 $\mu \mathrm{M}$ of sulforaphane ( $A$; A375 cells and B; HaCaT cells), phenethyl isothiocyanate (C; A375 cells and D; HaCaT cells) and benzyl isothiocyanate (E; A375 cells and F; HaCaT cells) for 24 and $48 \mathrm{~h}$. Data are representative of two independent experiments. An asterisk (*) or hashtag (\#) indicates statistical significance when compared to their respective controls (DMSO) for 24 or $48 h(p<0.05)$. 
highest potency, as it induced a significant reduction in cell viability levels at $5 \mu \mathrm{M}$ onwards (24-48 h) in both A375 (Figure 1C) and $\mathrm{HaCaT}$ (Figure 1F) cells.

When we utilized an in vitro model of ITC treatment by subjecting human malignant melanoma (A375) and nonmelanoma (A431) cells as well as human normal keratinocyte (HaCaT; control) cells to a range of low ITC concentrations (0.1-5 $\mu \mathrm{M}$ for $48 \mathrm{~h}$ but being refreshed after an initial $24 \mathrm{~h}$ of treatment) our data revealed that SFN and PEITC inhibited in a statistically significant manner $(p<0.05)$ cell viability levels at $5 \mu \mathrm{M}$ in A375 cells only (Figure $2 \mathrm{~A}$ and B respectively). However, at this concentration, cells exposed to SFN showed a more profound inhibitory effect on viability levels compared to PEITC (approximately $60 \%$ vs. $80 \%$ respectively). Finally, treatment with BITC also, statistically significantly decreased $(p<0.05)$ the viability levels at concentrations as low as 2.5 $\mu \mathrm{M}$ onwards in A375 and A431 cells only. However, this effect was more profound in A375 cells where a $2.5 \mu \mathrm{M}$ inhibition of cell viability was recorded to levels of $\sim 70 \%$ which was further decreased to $\sim 30 \%$ after treatment with 5 $\mu \mathrm{M}$ of BITC (Figure 2C).

Finally, in order to investigate whether treatment with ITCs induces an apoptotic response in A375 cells, the activity levels of the initiator caspases 4, 8 and 9 were evaluated. Activation of these caspases is indicative of the involvement of various apoptotic pathways in a manner where caspase 8 involves the extrinsic (29), caspase 9 the intrinsic (30) and caspase 4 the endoplasmic reticulum (ER)-dependent (31) pathways. Our data showed that treatment with BITC statistically significantly increased $(p<0.05)$ the activity levels of all initiator caspases whereas this was the case only for caspase 9 in PEITC-treated cells. Alternatively, treatment with SFN showed no statistically significant changes in the activity levels of any of the above-mentioned caspases (Figure 3A-C). Similarly, western blot analysis data indicate that each of the SFN, PEITC and BITC were responsible for inducing a statistically significant decrease $(p<0.05)$ in protein expression levels of the effector procaspases 3 (Figure 3D) and 6 (Figure 3E) while for procaspase 7 this was the case only for BITC treatment (Figure 3F). Consequently, when these procaspases become activated they cleave specific cellular proteins including poly(ADP-ribose) polymerase (PARP) (Figure 3D) and lamins $\mathrm{A}$ and $\mathrm{C}$ (Figure $3 \mathrm{E}$ ) such as in the case of procaspase 3 and 6 , respectively. Overall, our results demonstrate that ITCs induce caspase activation in a manner which treatment with BITC results in the largest decrease in procaspase levels, followed by PEITC and SFN.

\section{Discussion}

The majority of studies have utilized non-melanoma (8-14) and melanoma (15-19) experimental models based on a single bolus addition of large ITC concentrations where a wide range of biological effects were documented but without provision of appropriate control (non-tumorigenic) cells. Similarly, we have been able to document such anticancer activity in melanoma cells but also in control keratinocyte cells suggesting a non-specific potency towards any type of cell line (tumorigenic or not).

To overcome the barrier of non-specific potency, we have developed a novel experimental in vitro model of ITC treatment by subjecting human malignant melanoma (A375) and non-melanoma (A431) cells as well as human normal keratinocyte (HaCaT; control) cells to a range of low ITC concentrations (0.1-5 $\mu \mathrm{M})$ for $48 \mathrm{~h}$, that were refreshed after an initial $24 \mathrm{~h}$ of treatment. Overall, our results highlight the novelty of the in vitro experimental model developed not only of being capable in exerting a potent anti-cancer activity (at low ITC concentrations) but also of being specific to human malignant melanoma (A375) cells while leaving unaffected human non-melanoma (A431) and normal keratinocyte $(\mathrm{HaCaT})$ cells. Moreover, our results indicate that BITC (among all the three ITCs) exerts the highest anticancer potency and thus highlights its effectiveness as a potential anti-cancer strategy.

Finally, since ITCs have shown to exert a plurality of anticancer effects by targeting various cellular processes such as, apoptosis, autophagy, cell cycle, angiogenesis, epigenetic pathways, antioxidant defenses, etc. (20-28), we focused on apoptosis in order to elucidate which underlined pathways were involved in accounting for the observed reduction of viability levels in A375 cells. Overall, ITCs induced apoptosis by activating a number of initiator $(8,9,4)$ and effector $(3,6,7)$ caspases indicating the involvement of various apoptotic pathways including but not limited to, the extrinsic (caspase 8), intrinsic (caspase 9) and ER-dependent (caspase 4) pathways. To the best of our knowledge, this is the first report that (i) describes a novel experimental in vitro model based on the utilization of low ITC concentrations in a manner described herein and (ii) how it exerts an anticancer effect uniquely to melanoma cells (without affecting other non-melanoma and normal keratinocyte cells) by inducing apoptosis at concentrations substantially lower than those utilized in current bibliography.

\section{Acknowledgements}

This work was supported, in part, by a Heriot Watt University (HWU, Edinburgh, UK) and Northumbria University (NNU, Newcastle upon Tyne, UK) start-up funds (Professor Mihalis Panayiotidis) including a HWU (Mrs Theodora Mantso) and a NNU (Mrs Melina Mitsiogianni) PhD studentship and by a LLP Erasmus Programme (Mr Aris Sfakianos and Dr Aglaia Pappa). Furthermore, the Authors would like to thank Dr Sharon Broby (Dermal Toxicology and Effects Group; Centre for Radiation, Chemical and Environmental Hazards; Public Health England, UK) for kindly providing the human keratinocyte $(\mathrm{HaCaT})$ cell line. 
(A)

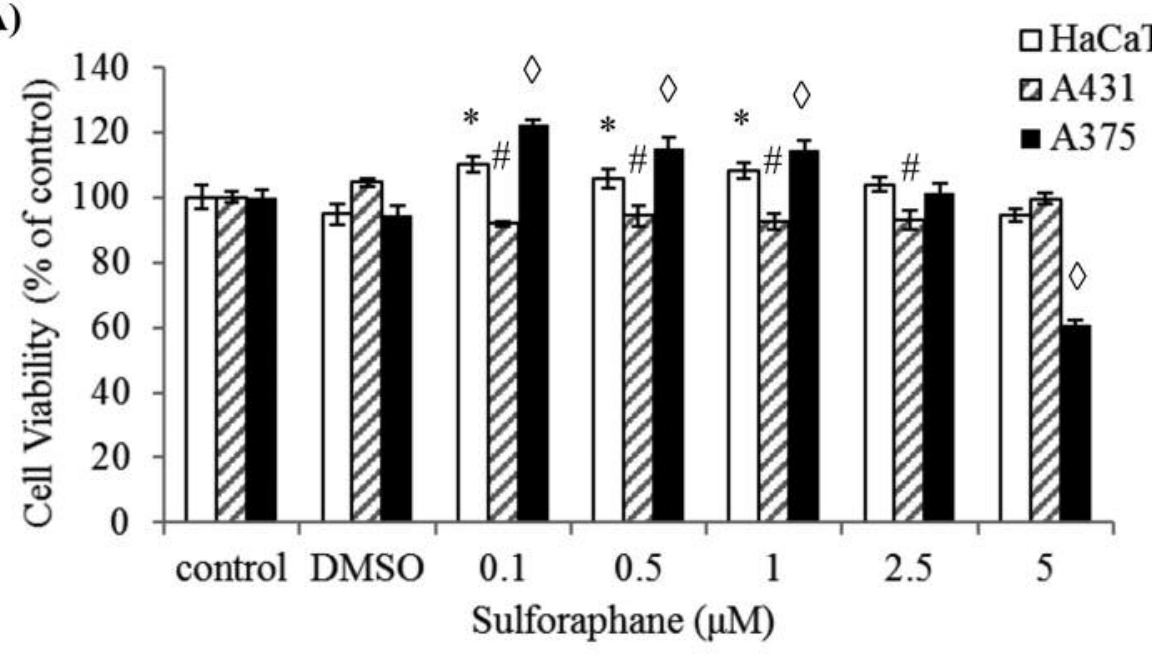

(B)

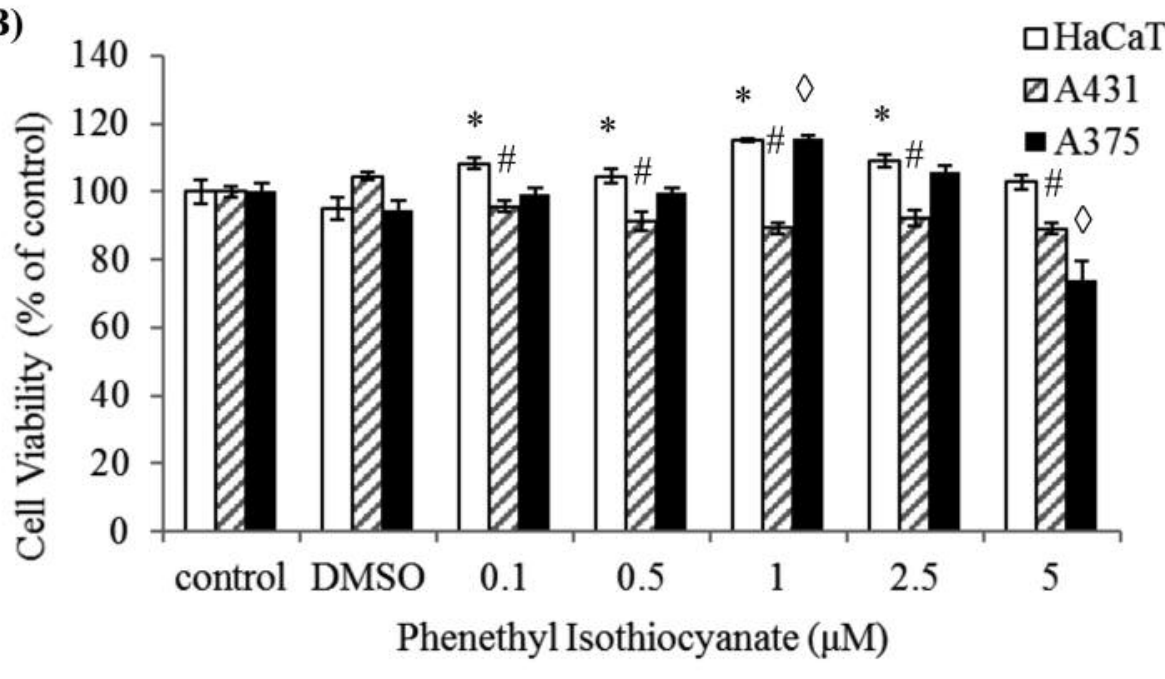

(C)

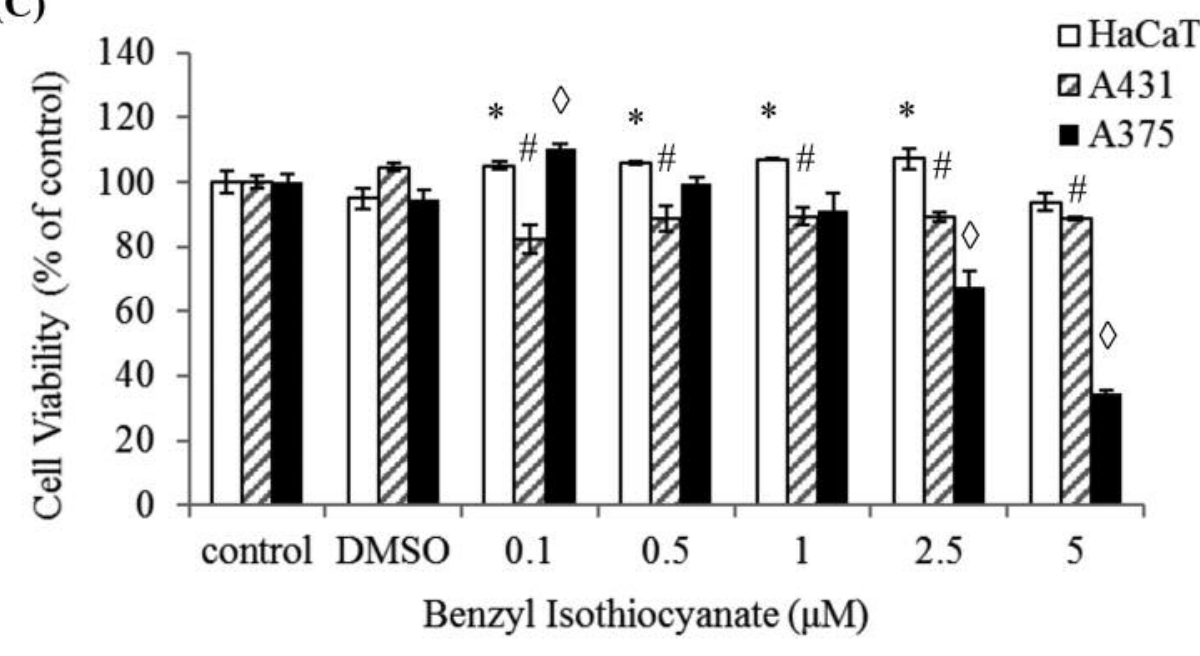

Figure 2. The effect of different concentrations of ITCs on HaCaT, A431 and A375 cells after 48 h of treatment. In general, cells were subjected to 0.1-5 $\mu \mathrm{M}$ of sulforaphane (A), phenethyl isothiocyanate $(B)$ and benzyl isothiocyanate $(C)$ at 0.1-5 $\mu M$ for $48 \mathrm{~h}$ with all treatments being refreshed after 24h. Data are representative from two independent experiments. An asterisk $(*)$, hashtag $(\#)$ or diamond $(\diamond)$ indicates statistical significance for HaCaT, A431 or A375 treated cells, respectively when compared to their corresponding controls (DMSO) $(p<0.05)$. 
(A)

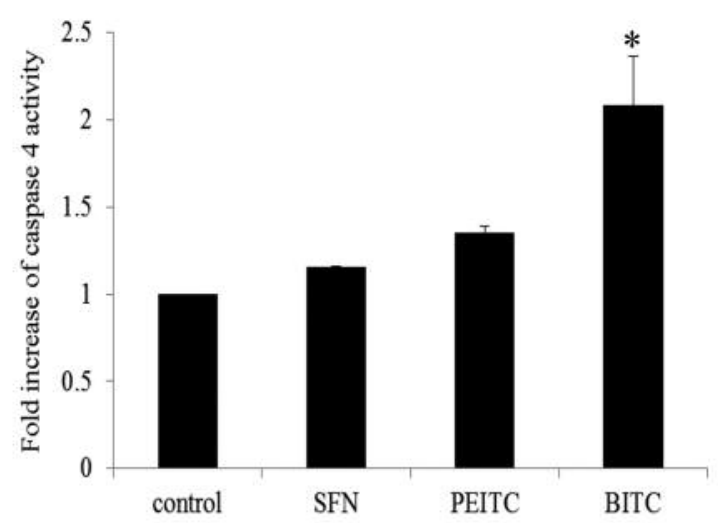

(B)

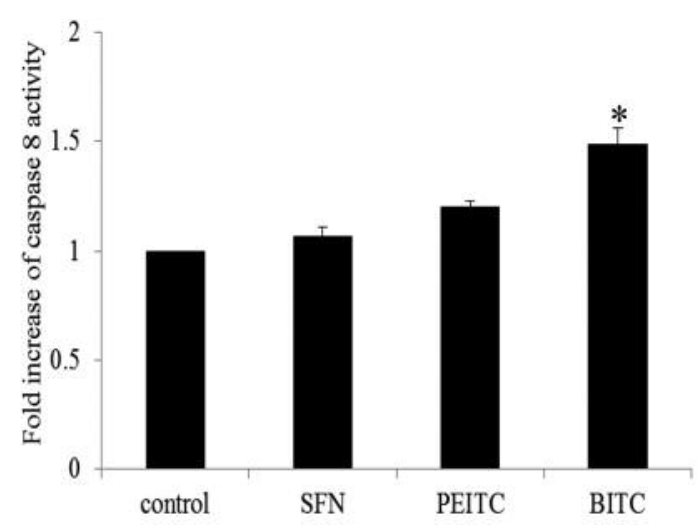

(C)

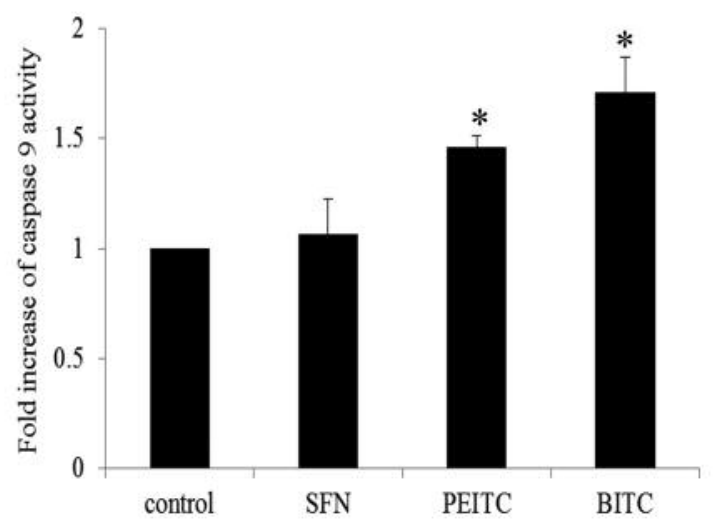

(D)

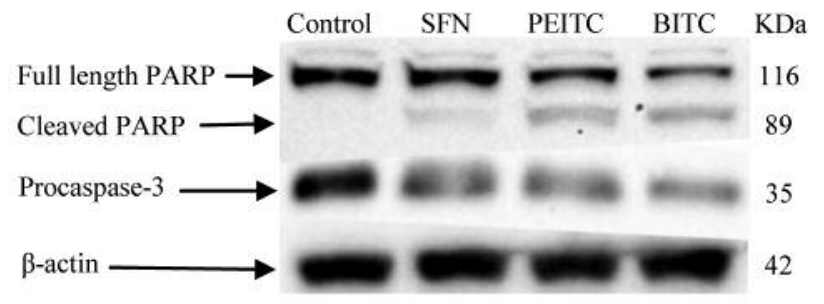

(E)

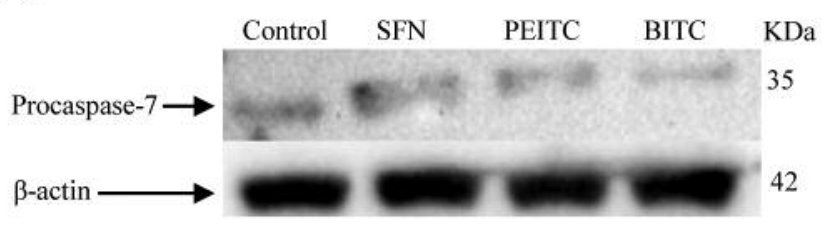

(F)

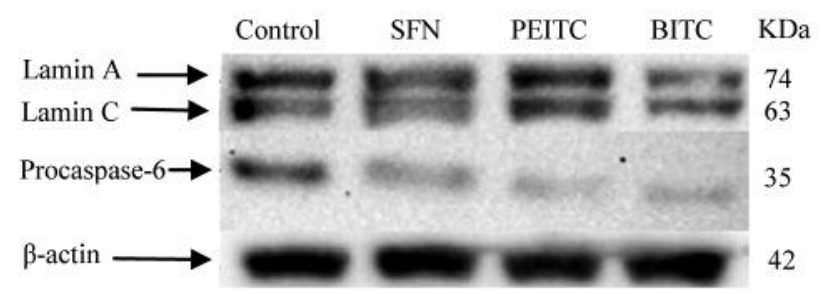

Figure 3. The effect of ITCs on enzymatic activity and protein expression levels of various caspases. A375 cells were subjected to $5 \mu M$ of ITC (for $48 \mathrm{~h}$ with all treatments being refreshed after $24 \mathrm{~h}$ ) and enzymatic activity levels were recorded for caspase $4(A)$, caspase $8(B)$ and caspase $9(C)$. Additionally, under the same treatment conditions, protein expression levels were assessed for procaspase-3 $(D)$, procaspase-6 $(E)$ and procaspase-7 $(F)$. Data are representative from two independent experiments. An asterisk $(*)$ indicates statistical significance when compared to their respective controls $(p<0.05)$. 


\section{References}

1 Markovic SN, Erickson LA, Rao RD, Weenig RH, Pockaj BA, Bardia A, Vachon CM, Schild SE, McWilliams RR, Hand JL, Laman SD, Kottschade LA, Maples WJ, Pittelkow MR, Pulido JS, Cameron JD and Creagan ET: Malignant melanoma in the 21 st century, part 1: Epidemiology, risk factors, screening, prevention, and diagnosis. Mayo Clin Proc 82(3): 364-380, 2007.

2 Abdull AF and Noor NM: Cruciferous vegetables: dietary phytochemicals for cancer prevention. Asian Pac J Cancer Prev 14(3): 1565-1570, 2013.

3 Bones AM and Rossiter JT: The myrosinase-glucosinolate system, its organisation and biochemistry. Physiol Plantar 97(1): 194-208, 1996.

4 Zhang YS: Cancer-preventive isothiocyanates: measurement of human exposure and mechanism of action. Mutat Res 555(1-2): 173-190, 2004

5 Clarke JD, Dashwood RH and Ho E: Multi-targeted prevention of cancer by sulforaphane. Cancer Lett 269(2): 291-304, 2008.

6 Yu R, Mandlekar S, Harvey KJ, Ucker DS and Kong AN: Chemopreventive isothiocyanates induce apoptosis and caspase3-like protease activity. Cancer Res 58(3): 402-408, 1998.

7 Nikhil K, Sharan S, Singh AK, Chakraborty A and Roy P: Anticancer Activities of Pterostilbene-Isothiocyanate Conjugate in Breast Cancer Cells: Involvement of PPAR gamma. PLoS One 9(8): e104592, 2014.

8 Cheng YM, Tsai CC and Hsu YC: Sulforaphane, a Dietary Isothiocyanate, Induces $\mathrm{G}_{2} / \mathrm{M}$ Arrest in Cervical Cancer Cells through CyclinB1 Downregulation and GADD45//CDC2 Association. Int J Mol Sci 17(9): e1530, 2016.

9 Lee CS, Cho HJ, Jeong YJ, Shin JM, Park KK, Park YY, Bae YS, Chung IK, Kim M, Kim CH, Jin F, Chang HW and Chang YC: Isothiocyanates inhibit the invasion and migration of C6 glioma cells by blocking FAK/JNK-mediated MMP-9 expression. Oncol Rep 34(6): 2901-2908, 2015.

10 Su JC, Lin K, Wang Y, Sui SH, Gao ZY and Wang ZG: In vitro studies of phenethyl isothiocyanate against the growth of LN229 human glioma cells. Int J Clin Exp Pathol 8(4): 4269-4276, 2015.

11 Lawson AP, Long MJ, Coffey RT, Qian Y, Weerapana E, El Oualid F and Hedstrom L: Naturally Occurring Isothiocyanates Exert Anticancer Effects by Inhibiting Deubiquitinating Enzymes. Cancer Res 75(23): 5130-5142, 2015.

12 Chen CY, Yu ZY, Chuang YS, Huang RM and Wang TC: Sulforaphane attenuates EGFR signaling in NSCLC cells. J Biomed Sci 22: 38, 2015.

13 Wang L, Tian Z, Yang Q, Li H, Guan H, Shi B, Hou P and Ji M: Sulforaphane inhibits thyroid cancer cell growth and invasiveness through the reactive oxygen species-dependent pathway. Oncotarget 6(28): 25917-25931, 2015.

14 Zhang Y, Tang L and Gonzalez V: Selected isothiocyanates rapidly induce growth inhibition of cancer cells. Mol Cancer Ther 2(10): 1045-1052, 2003.

15 Ni WY, Hsiao YP, Hsu SC, Hsueh SC, Chang CH, Ji BC, Yang JS, Lu HF and Chung JG: Oral administration of benzyl-isothiocyanate inhibits in vivo growth of subcutaneous xenograft tumors of human malignant melanoma A375.S2 cells. In Vivo 27(5): 623-626, 2013.

16 Hamsa TP, Thejass P and Kuttan G: Induction of apoptosis by sulforaphane in highly metastatic B16F-10 melanoma cells Drug Chem Toxicol 34(3): 332-340, 2011.

17 Do DP, Pai SB, Rizvi SAA and D'Souza MJ: Development of sulforaphane-encapsuled microspheres for cancer epigenetic therapy. Int J Pharmaceutics 386: 114-121, 2010.
18 Sharma AK, Sharma A, Desai D, Madhunapantula SV, Huh SJ, Robertson GP and Amin S: Synthesis and Anticancer Activity Comparison of Phenylalkyl Isoselenocyanates with Corresponding Naturally Occurring and Synthetic Isothiocyanates. J Med Chem 51(24): 7820-7826, 2008.

19 Thejass P and Kuttan G: Modulation of cell-mediated immune response in B16F-10 melanoma-induced metastatic tumor-bearing C57BL/6 mice by sulforaphane. Immunopharmacol Immunotoxicol 29(2): 173-186, 2007.

20 Rudolf K, Cervinka M, Rudolf E: Sulforaphane-induced apoptosis involves p53 and p38 in melanoma cells. Apoptosis 19(4): 734747, 2014.

21 Huang SH, Hsu MH, Hsu SC, Yang JS, Huang WW, Huang AC, Hsiao YP, Yu CC and Chung JG: Phenethyl isothiocyanate triggers apoptosis in human malignant melanoma A375.S2 cells through reactive oxygen species and the mitochondria-dependent pathways. Hum Exp Toxicol 33(3): 270-283, 2014.

22 Huang SH, Wu LW, Huang AC, Yu CC, Lien JC, Huang YP, Yang JS, Yang JH, Hsiao YP, Wood WG, Yu CS and Chung JG: Benzyl isothiocyanate (BITC) induces G2/M phase arrest and apoptosis in human melanoma A375.S2 cells through reactive oxygen species (ROS) and both mitochondria-dependent and death receptor-mediated multiple signalling pathways. J Agric Food Chem 60(2): 665-675, 2012.

23 Thejass P and Kuttan G: Allyl isothiocyanate (AITC) and phenyl isothiocyanate (PITC) inhibit tumour-specific angiogenesis by down regulating nitric oxide (NO) and tumour necrosis factor- $\alpha$ (TNF- $\alpha$ ) production. Nitric Oxide 16(2): 247-257, 2007.

24 Higdon JV, Delage B, Williams DE and Dashwood RH: Cruciferous vegetables and human cancer risk: epidemiologic evidence and mechanistic basis. Pharmacol Res 55(3): 224-236, 2007.

25 Bommareddy A, Hahm ER, Xiao D, Powolny AA, Fisher AL, Jiang Y and Singh VS: Atg5 Regulates Phenethyl IsothiocyanateInduced Autophagic and Apoptotic Cell Death in Human Prostate Cancer Cells. Cancer Res 69(8): 3704-3712, 2009.

26 Herman-Antosiewicz A, Johnson DE and Singh SV: Sulforaphane Causes Autophagy to Inhibit Release of Cytochrome c and Apoptosis in Human Prostate Cancer Cells. Cancer Res 66(11): 5828-5835, 2006.

27 Xiao D, Bommareddy A, Kim SH, Sehrawat A, Hahm ER and Singh SV: Benzyl isothiocyanate causes FoxO1-mediated autophagic death in human breast cancer cells. PLoS One 7(3): e32597, 2012.

28 Xiao D, Powolny AA, Moura MB, Kelley EE, Bommareddy A, Kim SH, Hahm ER, Normolle D, Van Houten B and Singh SV: Phenethyl isothiocyanate inhibits oxidative phosphorylation to trigger reactive oxygen species-mediated death of human prostate cancer cells. J Biol Chem 285(34): 26558-26569, 2010.

29 Sakamaki K, Imai K, Tomii K and Miller DJ: Evolutionary analyses of caspase- 8 and its paralogs. Deep origins of the apoptotic signalling pathways. Bioessays 37(7): 767-776, 2015.

$30 \mathrm{Kim} \mathrm{B}$, Srivastava SK and Kim SH: Caspase-9 as a therapeutic target for treating cancer. Expert Opin Ther Targets 19(1): 113127, 2015.

31 Di Fazio P, Ocker $M$ and Montalbano R: New drugs, old fashioned ways: ER stress induced cell death. Curr Pharm Biotechnol 13(11): 2228-2234, 2012.

Received October 17, 2016

Revised November 3, 2016

Accepted November 8, 2016 